\title{
Transporte marítimo de mercancías de corta distancia y responsabilidad del transportista. Una aproximación jurídico- internacional en el contexto de su promoción en el ámbito comunitario
}

\author{
Carlos Llorente Gómez de Segura \\ Abogado y \\ Profesor Asociado doctor de Derecho Internacional Privado \\ Universidad Carlos III de Madrid
}

\begin{abstract}
Resumen: La política europea de transporte quiere promocionar el transporte marítimo de corta distancia (TMCD) para revitalizar un sector en declive y convertirlo en alternativa al transporte terrestre de mercancías en determinadas circunstancias. No se trata de una labor a corto plazo ni fácil, en la que, además, se plantean incertidumbres de alcance jurídico-privado derivadas tanto de la complejidad estructural que caracteriza a las operaciones de transporte con TMCD (superposición de contratos) como de la diversidad de regímenes susceptibles de aplicación en cada caso a dichas operaciones. La superación de estas incertidumbres se conseguirá, por un lado, familiarizando a los operadores de transporte implicados en actividades de transporte con TMCD con preceptos como el artículo $2 \mathrm{CMR}$, regulador de un tipo de transporte superpuesto carretera-mar (ro-ro) especialmente idóneo para el desarrollo de dichas operaciones; y, de otro lado, con un mejor conocimiento de los puntos de encuentro y de divergencia entre las regulaciones aplicables al fenómeno de la responsabilidad del transportista en los sectores terrestre y marítimo. Este artículo pretende analizar en sus líneas generales el régimen del artículo 2 CMR y comparar los modelos terrestre y marítimo de responsabilidad del transportista.
\end{abstract}

Palabras clave: Transporte marítimo de corta distancia, Responsabilidad del transportista, Artículo 2 CMR, Regímenes de responsabilidad por carretera y mar: comparación.

Abstract: The EU transport policy is trying to promote short sea shipping (SSS) in order to bring it up to a modern shape and as an alternative to the carriage of goods by road under certain circumstances. It is neither a short-term task nor an easy one and, additionally, it brings about some legal uncertainties which derive from the structural complexity of the transport operations which include SSS (contract overlapping), as well as from the divergent legal regimes applicable in each case to those operations. In order to overcome those uncertainties, transport operators dealing with SSS should, on the one hand, get acquainted with rules such as the one contained in article 2 CMR, which covers an special kind of roadsea combined transport (ro-ro) that fits ideally in regular operations with SSS. And, on the other hand, they should get a better knowledge of the similarities and differences between the road and sea liability regimes. With this article we will try both to describe the basic meaning of article 2 CMR and to compare those two liability regimes. 
Key words: Short-Sea Shipping, Carrier's Liability, Article 2 CMR, Comparison of Road and Sea Liability Regimes.

Sumario: I. Presentación. - II. Las implicaciones jurídico-privadas de las operaciones de transporte con TMCD en el plano de la responsabilidad de los operadores de transporte: marco general. - III. Transporte superpuesto: la responsabilidad del transportista en el artículo 2 CMR. IV. La responsabilidad del transportista en el transporte internacional por carretera y por mar: análisis comparativo de ambos regímenes: 1. Carácter del régimen de responsabilidad. 2. Periodo de responsabilidad. 3. Fundamento de la responsabilidad. 4. Supuestos principales de responsabilidad. 5. Limitación de la deuda indemnizatoria. 6. Pérdida del beneficio de la limitación de la deuda indemnizatoria. 7. Aplicación del régimen de responsabilidad a las diversas acciones. 8. Protestas. 9. Prescripción. 10. Conclusiones.

\section{Presentación ${ }^{1}$}

El transporte marítimo de corta distancia (TMCD) está de moda. Y lo está gracias a la política comunitaria de transporte, que desde 1995 está promocionando activamente esta modalidad de transporte con el objetivo - entre otros, pero señaladamente- de aliviar la congestión del tráfico terrestre de mercancías (sobre todo por carretera) que afecta a nuestro continente, a través de la apertura de «autopistas del mar» que permitan una integración plurimodal de las operaciones de transporte, facilitando el transporte «puerta a puerta» ${ }^{2}$.

La promoción del TMCD en el nivel comunitario, dentro de este contexto, se ha centrado fundamentalmente en la superación de los distintos obstáculos - técnicos, administrativos, logísticos y económicos-que impiden su

${ }^{1}$ Este trabajo está basado en la ponencia que presentó su autor en la Jornada sobre la Seguridad Jurídica de la Mercancía en el TMCD, que se celebró en Castellón el 7 de junio de 2006 y fue organizada por la Fundación Instituto Portuario de Estudios y Cooperación de la Comunidad Valenciana (FEPORTS) y por la Asociación Española de Promoción del Transporte Marítimo de Corta Distancia (SPC-SPAIN), organismos a los que desde estas páginas deseo reiterar mi agradecimiento por su invitación y mis votos por la promoción de esta modalidad de transporte.

${ }^{2}$ Una forma rápida y concisa de conocer la evolución de los esfuerzos comunitarios en esta materia es consultar la «Comunicación de la Comisión al Consejo, al Parlamento Europeo, al Comité Económico y Social Europeo y al Comité de las Regiones, sobre el transporte marítimo de corta distancia», Bruselas, 2.7.2004, COM (2004), 453 final. En esta Comunicación hay abundantes referencias a otros textos y documentos que pueden situar al lector interesado en el buen camino de la comprensión del alcance y objetivos de la política comunitaria en esta materia. 
adecuado desarrollo y, si bien se están produciendo ya algunos resultados significativos, se trata de un ejercicio a largo plazo, como reconoce la propia Comisión.

Ahora bien, como parte de esa labor de fomento, no se ha previsto directamente el análisis de las implicaciones jurídico-privadas del TMCD, pero parece razonable pensar que si se pretende impulsar una determinada modalidad de transporte como alternativa (o complemento) a otras, habrá que dedicar cierta atención a esas cuestiones, para poner de manifiesto el marco de derechos y obligaciones en el que se van a mover los distintos agentes que operan en este sector. A este objetivo responden principalmente las reflexiones que siguen.

\section{Las implicaciones jurídico-privadas de las operaciones de transporte con TMCD en el plano de la responsabilidad de los operadores de transporte: marco general}

Un transporte marítimo de corta distancia, en sentido estricto ${ }^{3}$, no plantea particulares problemas de configuración jurídico-privada. No va a ser éste, por tanto, el objeto de nuestro análisis. Pero sí los puede plantear, en vía de hipótesis, la ejecución de operaciones de transporte (internacional) de mercancías por carretera en las que se recurra al TMCD durante una parte de su ejecución ${ }^{4}$. De hecho, ésta es una de las finalidades que sustentan la promoción del TMCD en el ámbito comunitario: conseguir que una parte del trayecto total, susceptible de realización íntegra por carretera, se ejecute por $\operatorname{mar}^{5}$.

\footnotetext{
${ }^{3}$ Es decir, como transporte exclusivamente marítimo e independiente de otras fases previas o posteriores a la marítima, que se efectúa entre dos puertos situados en zonas geográficas próximas o cercanas. Como tal, desde una perspectiva jurídico-contractual, el TMCD se estructuraría a través de un contrato de transporte de mercancías por mar sujeto a la correspondiente legislación interna o internacional, según fuese el caso.

${ }^{4}$ En este trabajo, a partir de ahora, nos referiremos a este supuesto como «operaciones de transporte con TMCD».

${ }^{5}$ Pongamos un ejemplo que, como suele decirse con razón, vale más que mil palabras. Imagínese que una mercancía debe ser trasladada desde un punto en el interior de España hasta un destino en el interior de Italia. En vía de principio, una opción razonable es la de transportar dicha mercancía desde su origen hasta su destino completamente por carretera. Pero otra opción puede ser la de trasladar la mercancía por carretera desde el interior de España hasta un puerto de nuestra costa mediterránea (p. ej., Barcelona), embarcar la mercancía (incluso sin descargarla, embarcar también el camión) en un buque con destino a un puerto italiano (corta distancia) (p. ej., Génova) y una vez allí proceder al transporte de la mercancía, otra vez por carretera, hasta el destino interior italiano. Algunas de las ventajas de esta segunda opción son, a juicio de los expertos, que el transporte total resulta más barato, es más benévolo ambientalmente, y descongestiona las carreteras.
} 
Pues bien, en este contexto, para fundar y medir la responsabilidad de los porteadores que intervienen en una operación de transporte con TMCD hay que realizar un doble ejercicio previo:

1) Averiguar dónde se sitúan dichos operadores en la estructura contractual en la que se inserta la fase de TMCD; e

2) Identificar la regulación aplicable a dicha estructura y, en particular, a cada una de las relaciones que la componen (y, por ende, a la determinación de la responsabilidad de los operadores que forman parte de ellas).

Con respecto a la primera cuestión habría que decir que si bien las operaciones de transporte con TMCD, en vía de hipótesis, no tienen por qué responder a un mismo modelo estructural, las tendencias marcadas por el tráfico a este respecto ponen de manifiesto la existencia de patrones más o menos homogéneos - homogeneidad que no es sinónimo de simplicidad-que se repiten en la configuración contractual de las operaciones de transporte con TMCD, destacando, por encima de otros, el del denominado transporte «superpuesto» carretera-mar (Ro-Ro), es decir, aquél en el que si bien las mercancías se trasladan sustancialmente por carretera ${ }^{6}$, en una fase determinada del traslado (habitualmente una fase intermedia) el vehículo de carretera, junto con la mercancía (sin ruptura de carga), son embarcados en un buque (ferry) especialmente preparado para realizar este tipo de desplazamientos $^{7}$. Por regla general, en este tipo de estructuras hay una superposición

\footnotetext{
${ }^{6}$ La combinación carretera-mar es la más frecuente, pero también cabrían, en este contexto, otras combinaciones multimodales junto con la fase marítima. Sobre estas cuestiones y el transporte multimodal en general, véase el trabajo de C. LLORENTE GómEZ DE SEGURA, «El contrato de transporte multimodal internacional de mercancías», en A. L. CALVo CARAvaCa y L. Fernández de la Gándara (Dirs.) y P. Blanco-Morales Limones (Coord.), Contratos internacionales, Madrid 1997, pp. 583 ss., en especial p. 588.

${ }^{7}$ Una alternativa al transporte ro-ro, también operativa en este ámbito, es que la combinación tierra-mar se produzca no por la carga del vehículo terrestre, junto con su mercancía, sobre el buque, sino por el uso de contenedores u otros medios de consolidación de cargas, que se transportan primero por vía terrestre, se descargan luego del vehículo terrestre para ser cargados en el buque hasta su destino, donde se vuelven a repartir por vía terrestre, en su caso. Sobre los problemas jurídicos derivados del transporte por contenedores, particularmente en el sector marítimo, véase AA.VV., Containerisation. Some implications of through transport from the banker's point of view, London, October 1966; K. GRÖNFORS, «Container transport and The Hague Rules», J.Bus.L. (1967) 298; W. D. ANGus, «Legal implications of the 'container revolution' in international carriage of goods» (1968) McGill L.J. 395-429; A. ARGYRIADIS, «Rechtsfragen des Übersee-Container-Verkehrs», RabelsZ (1969), 235; F. BERLINGIERI JR., «Probleme giuridici del trasporto in containers», Dir.Mar. (1971), 146; M.E. DEORCHIS, «The container and the package limitation. The search for predictability», 5 J.Mar.L. \& Com. 251-279 (1974); F. BIANCA, «Osservazioni sulla responsabilitá del vettore nel trasporto marítimo mediante containers», Dir. Trasp. (1991), 547.
} 
de contratos en la que, por un lado, el operador de transporte principal (agencia de transporte, transitario o el propio transportista por carretera) organiza (contrata) todo el transporte frente a su cliente (asumiendo la responsabilidad derivada del traslado completo) y, por otro lado, otro porteador se encarga de la ejecución parcial del transporte por mar por indicación del (y frente al) operador principal y sin vinculación contractual alguna con el cliente ${ }^{8}$.

El segundo ejercicio se plantea porque las operaciones con TMCD, también en vía de hipótesis, son habitualmente (en particular en el contexto comunitario) operaciones de carácter internacional, es decir, presentan algún elemento de extranjería en su estructura ${ }^{9}$; caracterización esta que obliga a tener que decidir, entre otras cuestiones, cuál es el Derecho aplicable a una o varias de las relaciones que componen la estructura contractual en la que se inserta el $\mathrm{TMCD}^{10}$. En un buen número de casos, la regulación aplicable a la operación de transporte con TMCD podrá ser reconducida a alguno de los instrumentos del Derecho uniforme del transporte (terrestre y marítimo) que están en vigor, señaladamente el $\mathrm{CMR}^{11}$ (a través, sobre todo, de su ar-

\footnotetext{
${ }^{8}$ A este tipo de estructuras con superposición de contratos se la suele denominar con el nombre de «transporte unitario» 0 «transporte con subtransporte». Sobre ésta y otras modalidades de transporte con pluralidad de porteadores, véase C. LlORENTE GómEZ DE SEGURA, «Régimen jurídico del transporte cumulativo de mercancías en el Derecho español. Una nueva aproximación», Diario La Ley, 6 y 7 de enero de 2003, núms. 5690 y 5691.

${ }^{9}$ A. L. Calvo Caravaca y J. Carrascosa González, Derecho internacional privado, I, 7. ${ }^{\text {a }}$ edición, Granada 2006, pp. 13 ss. No siempre habrán de ser operaciones internacionales, no obstante. Imagínese el supuesto de un transporte de mercancías por carretera entre Bilbao y Palma de Mallorca, en el que el camión con su carga viaja por vía marítima desde el puerto de Barcelona hasta un puerto sito en las Islas Baleares. En estos casos, el recurso al DIPr., como sector del ordenamiento jurídico regulador de las situaciones privadas internacionales, será innecesario. Y habrá que buscar la regulación aplicable en la normativa interna.

${ }^{10}$ Téngase en cuenta que, en ocasiones, la internacionalidad de la operación de transporte en la que se inserta el TMCD (y el eventual recurso al DIPr.) no vendrá dada por el carácter transfronterizo del traslado - origen y destino situados en dos Estados distintos (aunque será lo habitual) - sino que también se producirá en aquellos supuestos de transportes internos efectuados por transportistas establecidos en un Estado distinto de aquél en el que se lleva a cabo el transporte (es el caso del cabotaje comunitario, p. ej.). En general, sobre esta situación, y sus implicaciones de DIPr., véase C. LlORENTE GóMEZ DE SEGURA, «Integración europea y unificación de la reglamentación del contrato de transporte de mercancías por carretera: Algunos datos y reflexiones, en F. Martínez SAnz (Dir.) y M. ${ }^{a}$ Victoria Petit LAVAL (Coord.), I Congreso internacional de transporte: los retos del transporte en el siglo XXI, I, Valencia 2005, pp. 847 ss.

${ }^{11}$ CMR = Convenio de Ginebra, de 19 de mayo de 1956, relativo al contrato de transporte internacional de mercancías por carretera (BOE núm. 109, de 7 de mayo de 1974; corrección de errores en BOE de 15 de junio de 1995), modificado por el Protocolo de 5 de julio de 1978 (BOE núm. 303, de 18 de diciembre de 1982). Sobre este Convenio, véanse, entre los trabajos de orden general, J. BASEDOW, «CMR», en Münchener Kommentar zum Handelsgesetzbuch, Bd. 7, Viertes Buch, Handelsgeschäfte (\$\$ 407-457) Transportrecht, München 1997, pp. 857 ss.; M. A. ClARKE, International carriage of goods by road: CMR, 3rd. ed., London 1997; H. GLÖCKNER, Leitfaden zur CMR, 7 Auf., Berlin 1991; K. F. HAAK, The
} 
tículo 2, al que dedicaremos, por su importancia en esta materia, un apartado posterior) y las RHV (LTM) ${ }^{12}$. Pero no siempre será así ${ }^{13}$. Y, en todo caso,

liability of the carrier under the CMR, The Hague 1986 (trad. por J. WADE); H. WIDMANN, Übereinkommen über den Beförderungsvertrag im internationalen Straßengüterverkehr (CMR), Luchterhand, Neuwied/Kriftel/Berlin 1993.; C. Llorente GómEZ DE SEGURA, «El contrato de transporte internacional de mercancías por carretera», en A. L. CALVO CARAVACA y L. Fernández de la GÁNDARa (Dirs.) y P. Blanco-Morales Limones (Coord.), Contratos internacionales, Madrid 1997, pp. 467 ss.; ID., «Contratos internacionales de transporte por carretera, ferrocarril, marítimo y multimodal», en A. L. CALVO CARAVACA Y J. CARRASCOSA GonZÁLEZ (Dirs.), Curso de contratación internacional, Madrid 2003, pp. 363-379; R. LÖEWE, «Commentary on the Convention of 19 may 1956 on the contract for the international carriage of goods by road», ETL (1976) 311; F. MARTínEZ SANZ, La responsabilidad del porteador en el transporte internacional de mercancías por carretera (CMR), Granada 2002; A. MESSENT y D. GLASS, Hill \& Messent CMR: Contracts for the international carriage of goods by road, 3rd ed., London 2000; A. PESCE, Il contratto di trasporto internazionale di merci su strada, Padova 1984; F. J. SÁNCHEZ-GAMBORINO, El contrato de transporte internacional. CMR, Madrid 1996; J. THEunIS (Gen. ed.), International Carriage of Goods by Road (CMR) London 1987; y K.H. THÜME (Hrsg.), Kommentar zur CMR: Übereinkommen über den Beförderungsvertrag im internationalen Straßengüterverkehr, Heidelberg 1995. En particular, R. ZüCHNER, «Zum Frachtvertrag nach der CMR», VersR (1964), 223; J. WILLENBERG, «Der internationale Strassengüterverkehr nach dem inkrafttreten der CMR. Eine übersicht über die ersten Entscheidungen», NJW (1968), 1020 ; J. VREBOS, «Convention relative au transport international de marchandises par route (CMR)», ETL (1966), 678; R. ZüCHNER, «Der Haftungsregelung der CMR für den grenzüberschreiten Strassengüterverkehr», Der Betrieb (1965), 59.

${ }^{12}$ RHV = Convenio de Bruselas de 25 de agosto de 1924, para la unificación de ciertas reglas en materia de conocimientos de embarque (Gaceta de Madrid núm. 212, de 31 de julio de 1930) (Reglas de La Haya), modificado por los Protocolos de 23 de febrero de 1968 (Reglas de Visby) y de 21 de diciembre de 1979 (BOE de 11 de febrero de 1984); LTM = Ley de 22 de diciembre de 1949, de transporte marítimo de mercancías en régimen de conocimiento de embarque (BOE núm. 358, de 24 de diciembre de 1949). Sobre la compleja y debatida convivencia entre estos dos grupos normativos (RHV y LTM) en nuestro ordenamiento jurídico, véase J. M. ${ }^{a}$ Ruiz Soroa, S. Zabaleta Sarasúa y M. González Rodrí-

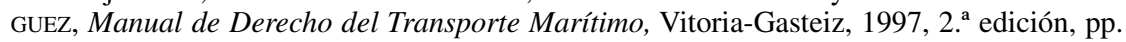
371 ss. En general, sobre el régimen de las RHV (LTM), AA.VV., The Hague-Visby Rules and the Carriage of Goods by Sea Act, London 1977; A. DiAmOND, «The Hague-Visby Rules», (1978) 2 LMCLQ 225-266; F. SÁNCHEZ CALERO, El contrato de transporte marítimo de mercancías. Las Reglas de La Haya-Visby, Elcano 2000 (con anterioridad, del mismo autor, El contrato de transporte marítimo de mercancías, Roma-Madrid 1957). Igualmente, M. A. Clarke, Aspects of the Hague Rules, The Hague 1976.

${ }^{13}$ Cuando la correspondiente cuestión litigiosa derivada de la operación de transporte en la que se inserta el TMCD no pueda ser resuelta con el recurso a uno de los instrumentos de Derecho uniforme del transporte, por caer fuera de su ámbito de aplicación o por no estar regulada en dicho instrumento (laguna), la determinación del Derecho aplicable a dicha cuestión, en nuestro ordenamiento, habrá de ser realizada acudiendo al Convenio de Roma de 19 de junio, sobre la ley aplicable a las obligaciones contractuales (BOE núm. 171, de 19 de julio de 1993; corrección de errores en BOE núm. 189, de 9 de agosto de 1993). Sobre este Convenio, en particular, véase C. Llorente GómEz DE SEgura, «El contrato de transporte y el Convenio de Roma sobre la ley aplicable a las obligaciones contractuales», en A. L. Calvo Caravaca y J. Carrascosa González, Estudios sobre contratación internacional, Madrid 2006, pp. 337 ss. 
puede suceder que el contrato principal tenga carácter internacional, pero no lo tengan, por el contrario, las relaciones internas de la operación.

A la luz de estas reflexiones previas, y dado el carácter abierto y multiforme de esta cuestión, creemos necesario centrar el objeto de nuestro análisis en las siguientes cuestiones:

1) Determinación del régimen de responsabilidad aplicable al transporte superpuesto carretera-mar, particularmente en el caso regulado por el artículo 2 CMR, por ser paradigmático y de frecuente aplicación en las operaciones de transporte europeas con TMCD.

2) Comparación del régimen de responsabilidad del empresario de transporte (porteador) en los transportes internacionales por carretera y marítimo, con la finalidad de poner de manifiesto las similitudes y diferencias existentes entre ambos regímenes. De este modo, sobre todo a la luz de sus diferencias, podrán advertirse las incertidumbres jurídico-privadas que pueden plantear las operaciones de transporte con TMCD. Y, visto desde una perspectiva positiva, podremos destacar, igualmente, los puntos de conexión (que son bastantes y significativos) entre los regímenes de responsabilidad de ambos modos de transporte.

\section{Transporte superpuesto: la responsabilidad del transportista en el artículo 2 CMR}

El artículo 2 CMR centra su atención en aquellos contratos de transporte internacional de mercancías por carretera, sometidos a dicho Convenio ${ }^{14}$

\footnotetext{
${ }^{14}$ El CMR es un Convenio de aplicación obligatoria, lo cual significa que su aplicación dependerá exclusivamente de que se den, en cada caso, las circunstancias previstas en su Capítulo I (en particular, su artículo 1), que es el que define, precisamente, el ámbito de aplicación del Convenio. No hay margen, por tanto, para la autonomía de la voluntad en este ámbito, como, en ciertas ocasiones y en algún ordenamiento en particular (nos referimos a Italia), se ha pretendido justificar por su doctrina y tribunales (véase, p. ej., sobre la excepción «italiana», G. VALAPERTA, «La CMR è facoltativa?», Trasporti 1976 [10], 100; S. CARBONE, «Il diritto uniforme in tema di trasporti ed il suo ambito di applicazione nell'ordinamento italiano: casi e materiali», Dir.Mar. [1978], 369; M. GRIGOLI, «Sull'applicabilità della Convenzione di Ginevra del 1956 relativa al trasporto internazionale di merci su strada», Giust. civ. [1981], 296; E. FADDA, «Presupposti per l'applicazione della CMR. Finalmente la giurisprudenza cambia orientamento», Dir.Mar. [1982], 415 [nota a App. Firenze 2 febbraio 1981]; ID., «Ancora sui presupposti per l'applicazione della CMR», Dir.Mar. [1984], 554; M. FRIGO, «La pretesa derogabilità della CMR e i caratteri del diritto uniforme», Riv. dir. int. priv. proc. [1983], 94; M. MARESCA, «Ambito di applicazione della Convenzione di Ginevra sul trasporto di merci su strada del 1956 e ruolo della volontà delle parti», ETL [1983], 70; G. SILINGARDI, «La CMR: da normativa uniforme di applicazione necessaria a disciplina patizzia», Diritto del commercio internazionale [1987], 613). En suma, las partes de un con-
} 
conforme a su artículo $1.1^{15}$, en los que «el vehículo que contiene la mercancía sea transportado por mar (...) en una parte de su recorrido sin ruptura de carga».

Se trata, por lo tanto, de transportes superpuestos ${ }^{16}$ (en este caso, carretera-mar) ${ }^{17}$.

El artículo 2 CMR, como pone de manifiesto su inclusión en el Capítulo I del CMR (junto con el artículo 1), tiene como misión delimitar el ámbito de aplicación de dicho Convenio ${ }^{18}$ con respecto a este tipo de transportes

trato de transporte internacional de mercancías por carretera que caiga bajo el ámbito de aplicación definido por el artículo 1 CMR no pueden válidamente excluir la aplicación de este Convenio a su contrato, sin que quepa concluir lo contrario de la exigencia prevista en el artículo 6.1(k) CMR, que obliga a las partes del contrato a incluir en el documento de transporte (carta de porte) una cláusula de las llamadas «paramount», por la que se indica que el contrato de transporte formalizado en dicho documento está sometido, a pesar de cualquier cláusula contraria, al régimen establecido en el CMR (sobre este tipo de cláusulas, J. J. Álvarez Rubio, Las cláusulas paramount: autonomía de la voluntad y selección del derecho aplicable en el transporte marítimo internacional, Madrid 1997; E. SELVIG, «The paramount clause», 10 Am. J. Comp. L. 205-226 [1961]; en general, sobre esta cuestión y otros problemas conexos, E. CASTEllanos Ruiz, Autonomía de la voluntad y Derecho uniforme en el transporte internacional, Granada 1999). Aquella exigencia, cuya vulneración acarreará una determinada imputación de responsabilidad al porteador (artículo 7.3 CMR), opera, por tanto, en un plano distinto al de otras «cláusulas paramount», cuya existencia sí constituye un verdadero presupuesto de aplicabilidad de la normativa uniforme, como sucede, por ejemplo, en el ámbito marítimo (véase, en este sentido, el artículo 10, letra [c] RHV).

${ }^{15}$ De acuerdo con este precepto, el CMR «se aplicará a todo contrato de transporte de mercancías por carretera realizado a título oneroso por medio de vehículos, siempre que el lugar de la toma de carga de la mercancía y el lugar previsto para la entrega, indicados en el contrato, estén situados en dos países diferentes, uno de los cuales al menos sea un país contratante, independientemente del domicilio y nacionalidad de las partes del contrato». Sobre este precepto, A. PESCE, «Chapter 1. The Contract and Carriage under the CMR (Arts. 1, 41)», en J. THEunis (Ed.), International Carriage of Goods by Road, London 1987, pp. 1 ss.

${ }^{16}$ En general, R. ZÜCHNER, «Zur Rechstnatur der Beförderungsvertrages beim Huckepackverkehr», VersR (1966), 100; P. BRUNAT: «Le régime juridique des transports internationux route/mer», $B T$ (1976), 227; R. H. WIJFFELS, «Transports par car-ferries (note sous Comm. Paris, 14 mars 1973)», BT (1974), 271.

${ }^{17} \mathrm{El}$ art. 2 CMR fue introducido en el Convenio de Ginebra a instancias del Reino Unido (Clarke, Carriage of goods by road... cit., § 3.1.2.2.1) para que, de este modo, los numerosos transportes internacionales por carretera que partiesen de -o llegasen a- dicho país (habiendo de utilizar necesariamente la vía marítima) pudieran quedar sujetos también al CMR. De ahí que esté integrado, junto con el art. 1, en el Capítulo 1. ${ }^{\circ}$ del CMR («Ámbito de aplicación»). Igualmente, A. E. DonALD, «CMR-An outline and its history», [1995] 4 $L M C L Q 420-429$ y «CMR: an outline and its history-Goods to and from the continent», ETL (1976), 166; D. J. HILL, «Combined transport to Europe», [1975] 3 LMCLQ 303-307; «Carriage of goods by road to the continent», ETL (1976), 182.

${ }^{18}$ A. Chao, «Le champ d'application de la CMR», BT (1986), 733; M. A. Clarke, «Scope of CMR. Shell Chemicals v. P. \& O. Roadways» (Case and Comment)», [1993] 2 LMCLQ 156-158 = [1993] 1 Lloyd's Rep. 114. 
superpuestos, particularmente en lo que se refiere al problema de la responsabilidad del transportista de mercancías por carretera.

Y lo hace a través de tres reglas recogidas en su apartado 1: una regla general (inciso primero); una excepción (inciso segundo), y, finalmente, una cláusula de cierre (inciso tercero).

La regla general establece que, en los casos de transportes superpuestos previstos en su artículo 2, el CMR «se aplicará al conjunto del transporte», no obstante su naturaleza plurimodal. Según esta regla, por lo tanto, a esos transportes superpuestos les serán de aplicación todas las normas contenidas en el CMR, incluidas las relativas a la responsabilidad del transportista de carretera (Capítulo IV), si bien — hay que insistir- no sólo éstas ${ }^{19}$.

La excepción, por su parte, establece que, en las condiciones y circunstancias previstas en el precepto (que analizaremos inmediatamente), las normas por las que se regule la responsabilidad del transportista por carretera serán aquellas que resulten de aplicación al tramo marítimo. Por lo tanto, en esta hipótesis, el transportista por carretera verá su régimen de responsabilidad (por pérdida, avería o retraso) sometido no a las normas del Capítulo IV del CMR (artículos 17-29) sino, eventualmente, a otro conjunto normativo, en concreto, en nuestro caso (por tratarse de un TMCD), el que resulte de aplicación al segmento marítimo. En suma, el objetivo del artículo 2 CMR es conseguir que, en determinadas circunstancias, la responsabilidad del transportista por carretera cuyo vehículo sea trasladado - junto con su carga (es decir, sin ruptura de carga) - por otro modo de desplazamiento distinto durante una parte del recorrido total contemplado en el contrato, sea medida no según las normas de responsabilidad previstas en dicho Convenio, sino conforme a las normas propias del modo de transporte - distinto de la carretera- en el que pueda localizarse el origen del hecho desencadenador de dicha responsabilidad (sistema de responsabilidad tipo «network» o «red»). De este modo, no sólo se respetará la aplicación de la reglamentación jurídica directamente vinculada a la causación del daño, sino que, además, se conseguirá equiparar el sistema de responsabilidad al que quedará sometido el transportista por carretera (responsable principal ante el acreedor del transporte: artículo $3 \mathrm{CMR}$ ) con el del porteador del modo distinto a la carretera (porteador marítimo) que haya causado el incumplimiento (facilitándose, de esta manera, el ejercicio de la acción de regreso por parte del primer operador frente a este último).

${ }^{19}$ Las normas de Derecho aplicable que se recogen en el CMR abarcan un contenido que suele ser el usual en otros instrumentos de Derecho uniforme del transporte y que, básicamente, se centran en la regulación de dos grandes ámbitos de problemas: por un lado, los derivados de la documentación del contrato y, por otro, los relativos a la responsabilidad del transportista. Pero estas normas se complementan, a su vez, con otras relativas al contenido del contrato (derecho y obligaciones de las partes), al ejercicio de reclamaciones (en un ámbito precontencioso) y a los problemas derivados del transporte sucesivo. 
Finalmente, la cláusula de cierre establece que si, en el supuesto anterior, no existiesen disposiciones normativas aplicables al tramo marítimo, «la responsabilidad del transportista de carretera será determinada por el presente Convenio». Se vuelve, de este modo, a la aplicación de las reglas sobre responsabilidad recogidas en el Capítulo IV del CMR (se «cierra» así el sistema).

La excepción del inciso segundo del artículo 2.1 CMR, que es la que concede verdadera virtualidad a dicho precepto, como hemos avanzado, establece varios requisitos para su aplicación, cuya oscuridad y complejidad en ciertos extremos han sido objeto de crítica ${ }^{20}$. Intentaremos, a continuación, ofrecer una síntesis clarificadora de su significado.

Los requisitos son los siguientes:

1) La pérdida, avería o retraso en la entrega de la mercancía deberán haber sobrevenido durante el transporte no realizado por carretera (en nuestro caso, el marítimo).

2) La pérdida, avería o retraso en la entrega de la mercancía no habrán debido ser causados por algún acto u omisión del transportista por carretera, sino por un hecho que no ha podido producirse más que durante y por razón del transporte no realizado por carretera (en nuestro caso, el marítimo).

La prueba de estos requisitos (origen y causa marítimos) corresponderá a quien alegue la excepción del artículo 2.1 CMR (habitualmente, será el transportista por carretera).

${ }^{20}$ Sobre este controvertido precepto, R. RODIÈRE, «Les transports combinés route/autre mode de locomotion. Contribution à l'étude de l'article 2 de la CMR», BT (1973), 458; J. THEUNIS, «The liability of a carrier by road in roll on-roll off traffic», en J. THEUnIS (Gen. Ed.), International Carriage of Goods by Road (CMR), London 1987, pags. 235 ss.; J. RAMBERG, «Deviation fron the legal regime of the CMR (Art. 2)», en J. THEunIS (Gen. ed.), International Carriage of Goods by Road (CMR), London 1987, pags. 19 ss.; PUTZEYs, J., «Le droit superposé ou les paradoxes de l'article 2 CMR», ETL (1990), 107; ID., «L'article 2 de la CMR, une autre interpretation», BT (1991), 87; J. TheunIs, «Die Haftung des Straßenfrachtführers bei der Ro-Ro Beförderung», TranspR (1990), 263; M. ВоMBEECK, Ph. HAMER y B. VerhaEgEN, «La responsabilité du transporteur routier dans le transport par car-ferries. L'article 2 de la Convention relative au contrat de transport international de marchandises par route (CMR)», ETL (1990), 110; A. vAN BEELEN, «De aansprakelijheid van de wegvervoerder bij stapelvervoer conform art. 2 CMR», ETL (1991), 743. Igualmente, R. ACHARD, Nota sobre el «Anna Oden», BT (1986), 689; ID., «Transport en pontée. Paramount clause et l'article $2 \$ 1$ de la CMR. A propos de l'arrêt de Cassation Anna Oden», DMF (1989), 219; W. CZAPSKI, «Responsabilité contractuelle lors des transports internationaux routiers entre le continent européen et la Grande Bretagne (à travers la Manche)», I.R.U. (document interne), Genève 1984. Del mismo autor: «Responsabilité contractuelle lors du transport de véhicles routiers par car-ferries», I.R.U. (document interne), Genève 1986»; «Responsabilité du transporteur routier lors du transroulage et du ferroutage», ETL (1990), 172; «El transporte marítimo de camiones, remolques y semirremolques a corta distancia: aspectos jurídicos», RGD (1992), 4303. También puede consultarse el trabajo de P. G. FITZPATRICK, «Combined transport and CMR Convention», J. Bus. L. 311-319 (1968). 
Una vez probados estos requisitos, como dijimos, «la responsabilidad del transportista por carretera no será determinada por (el CMR), sino de la forma en que se determinaría la responsabilidad del transportista que no efectuó el transporte por carretera».

Ahora bien, para identificar el régimen que resultaría de aplicación a la responsabilidad del transportista marítimo, el artículo 2.1 CMR plantea la necesidad de realizar un doble ejercicio:

1) Hay que situarse en la hipótesis de que «se hubiera establecido un contrato de transporte entre el remitente (del contrato de transporte sometido al CMR) y ese otro transportista que no efectuó el transporte por carretera, para el exclusivo transporte de esa mercancía» (el llamado «contrato hipotético»).

2) Hay que identificar cuáles habrían sido «las disposiciones legales vigentes aplicables al transporte de mercancías por ese modo distinto de la carretera». O, dicho de otro modo, las disposiciones aplicables al «contrato hipotético». Probablemente, esta identificación es la que mayores problemas ha planteado con ocasión de la aplicación e interpretación del artículo 2.1 CMR, como por otro lado ya anticipa la cláusula de cierre del inciso final del precepto («si tales disposiciones no existen»), pues no siempre los elementos de hecho de la situación encajan en el ámbito de las normas hipotéticamente susceptibles de aplicación en cada caso.

Cuatro ideas más antes de cerrar este apartado:

1) La responsabilidad del transportista de carretera por la pérdida, avería o retraso causados durante el transporte por mar, en el marco del artículo $2 \mathrm{CMR}$, se funda en el artículo $3 \mathrm{CMR}$, que establece el principio general de responsabilidad del transportista (de carretera) por sus auxiliares ${ }^{21}$, entre los que se encuentra, en nuestro caso, el transportista que lleva a cabo el tramo marítimo. Ahora bien, ese principio general tiene un límite, el de que los auxiliares hayan actuado «en el ejercicio de sus funciones». Fuera de este límite, por lo tanto, al transportista por carretera no se le podrá hacer responsable por los actos u omisiones ilícitos del transportista marítimo.

2) Según el artículo 2.2 CMR, si el transportista de carretera y el transportista marítimo que interviene en el TMCD fuesen «una misma per-

${ }^{21}$ En general, F. JoRDANO Fraga, La responsabilidad del deudor por los auxiliares que utiliza en el cumplimiento, Madrid 1994; y P. ZELAYA: La responsabilidad civil del empresario por los daños causados por sus dependientes. Naturaleza y requisitos, Aranzadi, Pamplona 1995. Véanse, igualmente, los trabajos de O. TORRALBA, «La responsabilidad de los auxiliares en el cumplimiento de las obligaciones», $A D C$ (1971), 1143, y A. CRISTÓBAL, «La responsabilidad del deudor por sus auxiliares», $A D C$ (1989), 5. 
sona, su responsabilidad se determinará igualmente por el apartado anterior, como si ambas funciones hubiesen sido efectuadas por dos personas distintas». Este es un precepto de especial relevancia para las empresas de transporte que decidan realizar transportes internacionales de carretera con recurso al TMCD empleando vehículos y buques integrados ambos en su organización empresarial.

3) Aunque pueda resultar obvio, hay que recordar que el artículo 2 CMR es un precepto que regula la responsabilidad del transportista (internacional) de mercancías por carretera, pero no la responsabilidad del transportista (marítimo) que ha colaborado en la ejecución del transporte superpuesto. La responsabilidad de éste se regirá por las normas aplicables al contrato que le une con el transportista de carretera, quien, por regla general, será quien ejercite la correspondiente acción de responsabilidad contra él (habitualmente, en vía de regreso).

4) Si el reclamante quisiera (y pudiera) dirigirse directamente contra el transportista marítimo para exigirle responsabilidad por vía extracontractual, podría entrar en juego el artículo 28.2 CMR, según el cual «cuando, por pérdida, avería o retraso, se reclame en juicio responsabilidad extracontractual a personas de las que responde el transportista según el artículo 3, estas personas pueden prevalerse de las disposiciones de este Convenio que excluyan la responsabilidad del transportista o que determinen o limiten las indemnizaciones debidas». En nuestra interpretación de este precepto en su aplicación a supuestos de TMCD cubiertos por el artículo 2 CMR, por tanto, cabría entender que si el reclamante se dirige extracontractualmente contra el transportista marítimo que interviene en el TMCD, éste podrá ampararse en el artículo 2 CMR, es decir, podrá invocar, en su protección, la aplicación de las normas reguladoras de la responsabilidad aplicables al transporte marítimo (p. ej., RHV), siempre que se den los requisitos y condiciones previstas en aquel precepto.

\section{La responsabilidad del transportista en el transporte internacional por carretera y por mar: análisis comparativo de ambos regímenes}

La oportunidad de realizar, en el contexto de este trabajo, un análisis comparativo de la responsabilidad del transportista en el transporte internacional por carretera y por mar se destaca tras las reflexiones que hemos dedicado al artículo $2 \mathrm{CMR}$, modelo estructural prototípico de las operaciones de transporte con TMCD, en el que se combinan (o solapan) los regímenes de responsabilidad de ambos modos de transporte. El análisis es particularmente relevante para el transportista por carretera que, eventualmente, puede verse sometido al régimen de responsabilidad propio de otro modo de transporte (el marítimo). 
Por razones obvias, este análisis comparativo deberá ser necesariamente breve y se centrará en las principales cuestiones que afectan a todo régimen de responsabilidad del transportista.

La comparación se establecerá entre el sistema previsto en el $\mathrm{CMR}^{22}$ y el recogido en las RHV-LTM (y, eventualmente, para el sector marítimo, en las $\mathrm{RH}^{23}$ y en la PALGNM) ${ }^{24}$.

${ }^{22}$ Téngase en cuenta, por otro lado, que el CMR es el modelo que se está siguiendo actualmente en nuestro país por la Comisión de reforma de nuestra legislación del transporte terrestre, por lo que las referencias al CMR en este trabajo no se sustentan sólo en su proyección exclusivamente internacional. Sobre la corriente, generalizada en Europa, de extender la regulación del CMR al tráfico interno, véase, en general, C. LLORENTE GóMEZ DE SEgURA, «La incidencia del CMR en la armonización de la regulación del contrato de transporte en los Estados miembros de la Comunidad Europea», en A. L. Calvo Caravaca y S. AREAl Ludeña (Dir.), Cuestiones actuales del Derecho mercantil internacional, Madrid 2005, pp. 745 ss. En particular, J. PutZEYs, «The Belgian "Midway" for Applicability of CMR to Inland Road Transport: Palliative or Final Solution», en K. F. HAAK y E. C. SwarT (Eds.) Road Carrier's Liability in Europe, Part 2, The Hague 1995; G. PETERSSON y J. WeTTER, «The integration of the CMR rules in Swedish domestic road transportation regulations», [1978] 4 LMCLQ 567. Para la situación en Dinamarca, véase, U. ANDERSEN, «The Applicability of CMR in National Transport Law», en K. F. HAAK y E. C. SwART (Eds.), Road carrier's liability in Europe, 2, The Hague 1995; J. L. SARAGOÇA, «El contrato de transporte en Portugal: la aplicación de la Convención internacional CMR a los servicios interiores como fórmula para actualizar su régimen jurídico», $R G D$ (1992), 4331. ID., «Application of the CMR Convention on contracts for the carriage of goods by road in Portugal», en K. F. HAaK y E. C. SWART (Eds.), Road carrier's liability in Europe, 2, The Hague 1995 (= «La aplicación de la Convención CMR a los contratos de transporte nacional de mercancías por carretera en Portugal», RGD (1995), 10223); F. J. SÁnCHEZ-GAMBorino, «Portugal avanza hacia la modernización de su derecho sobre el contrato de transporte, en línea a la Convención CMR», $R G D$ (1995), 2341; M. CLARKE, «Contracts for the Carriage of Goods by Road: Cabotage in the United Kingdom», J.B.L. (1998), 591-595; F. BERNARDEAU, «La CMR en tant que régle des transports intérieurs», ETL (1998), 793. La última reforma alemana (HGB) en materia de transporte, también ha seguido un camino similar: por todos, C. LloRENTE GómEZ DE SEGURA, «La nueva regulación del contrato de transporte en Alemania. Transportsrechtsreformgesetz (TRG)», RDM (1999), 1601.

${ }^{23} \mathrm{RH}=$ Reglas de Hamburgo = Convenio de Hamburgo de 31 de marzo de 1978, sobre el transporte marítimo de mercancías (no vigente en España). La bibliografía sobre las RH es muy abundante, sobre todo en la doctrina extranjera. Entre otros, F. BERLINGIERI JR., «La nuova Convenzione sul trasporto di merci per mare», Dir. Mar. (1978), 185; K. GrÖNFORS, «Die Hamonisieriung des Transportrechts und die Hamburger Regeln», RabelsZ (1978), 696; S. MANKABADY (Ed.), The Hamburg Rules on the carriage of goods by sea, Leyden-Boston 1978; AA.VV., The Hamburg Rules, London 1978; R. RodièrE, «La responsabilité du transporteur maritime suivant les Règles de Hambourg (le point de vue d'un juriste latin)», DMF (1978), 451; J. C. SweEney, «Les Règles de Hambourg. Point de vue d'un juriste anglo-saxon», DMF (1979), 323; C. LEGENDRE, «La Convention des Nations Unies sur le transport de marchandises par mer», DMF (1978), 387; J. C. MoORE, «The Hamburg Rules», 10 J.Mar.L. \& Com. 1-11 (1978-1979); M. AlTER, «La Convention sur les transports de marchandises par mer (Règles de Hambourg)», JDI (Clunet) (1979), 793; G. AuCHTER, «La Convention des Nations-Unies sur le transport de marchandises par mer de 1978 (Règles de 


\section{Carácter del régimen de responsabilidad}

En el transporte por carretera, esta cuestión está regulada en el artículo $41 \mathrm{CMR}$, que acoge el régimen más estricto de todos los instrumentos de Derecho uniforme del transporte, al establecer que «toda estipulación que,

Hambourg, 1978)», ETL (1979) 3, 215; W. TETLEY, «The Hamburg Rules: A commentary», (1979) 1 LMCLQ 1-20; C. DouAY, «La Convention des Nations Uníes sur le transport de marchandises pare mer (Régles de Hambourg)», BTICF-ZIE (1979), 17; W. E. AstLE, The Hamburg Rules, London 1981; F. SÁnCHEZ CALERO, Las Reglas de Hamburgo sobre el contrato de transporte marítimo de mercancías. Una valoración crítica, Barcelona 1981; J. A. GómEZ SEGADE, «El transporte marítimo de mercancías: de las Reglas de La Haya a las Reglas de Hamburgo», RDM (1980), 221; R. MATILLA, «Reglas de Hamburgo. Principios fundamentales», RGLJ (1981), 281; AA.VV., «Le Regole di Hamburgo», Dir. Mar. (1983), 172, 501 y 734; V. MENGANo, Le Regole di Hamburgo e la responsabilitá del vettore, Napoli 1983; J. M. AlCÁNTARA, «Las Reglas de Hamburgo ante su inminente entrada en vigor. Una valoración actualizada», Der. Neg. (1990-1991), 398; R. A. GONZÁLEZ LEBRERO, «Las Reglas de Hamburgo», Tapia (1991), núm. 6, pp. 73 ss.; C.F. LÜDdEKE y A. JoHnson, A guide to the Hamburg Rules. From Hague to Hamburg via Visby. An industry report, London 1991; A. EMPARANZA Sobejano, «El transporte marítimo bajo conocimiento de embarque: Su régimen jurídico internacional tras la entrada en vigor de las Reglas de Hamburgo», en J. M. ${ }^{\text {a }}$ DE EizAguirRe (Coord.), El Derecho del transporte marítimo internacional, San Sebastián 1994, pp. 41-77; R. ILlESCAS ORTIZ, «Las Reglas de Hamburgo (Convenio de las Naciones Unidas sobre el transporte marítimo de mercancías, 1978), en AA.VV., Derecho uniforme del transporte internacional, Madrid 1998, pp. 67 ss. El sistema de las RH difiere sustancialmente del previsto en las RHV. Para un análisis comparativo entre unas y otras, véase G. F. ChANDLER III, «A comparison of Cogsa, the Hague/Visby Rules and the Hamburg Rules», 15 J.Mar.L. \& Com. 233-291 (1984). Con una misma perspectiva, B.W. YANCEY, «The carriage of goods: Hague, Cogsa, Visby and Hamburg», 57 Tul.L.Rev. 1238-1259 (1983); P. BONASSIES, «La responsabilitè du transporteur maritime dans les Règles de la Haye et dans les Règles de Hambourg», Dir.Mar. (1989), 949. En un estadio previo, F. BERLINGIERI Jr., «La Convenzione di Bruxelles del 25 agosto 1924 sulla polizza di carico ed il progetto Uncitral di convenzione sul trasporto di merci per mare: un raffronto critico», Dir. Mar. (1977), 557. Igualmente, J. M. ${ }^{a}$ GondRA, «El proyecto de reforma del Convenio de Bruselas de 25 de agosto de 1924, sobre transportes marítimos en régimen de conocimiento», RDM (1965), 313.

${ }^{24}$ PALGNM = Propuesta de Anteproyecto de Ley General de la Navegación Marítima (Ministerio de Justicia, Madrid 2004). Las menciones en este trabajo al régimen previsto en estos dos textos normativos (RH y PALGNM) se justifican en una personal apuesta de futuro. La PALGNM puede llegar a ser la próxima regulación del transporte marítimo en nuestro país, la cual se inspira señaladamente, por otro lado, en las RH en materia de responsabilidad (véanse las páginas 14 y 51 de su «Memoria»), y propone además la ratificación de dicho Convenio por parte del Estado español («Memoria», página 81). No hay aún, entre nosotros, demasiadas referencias bibliográficas sobre la PALGNM, por lo que debemos remitirnos a los trabajos que sobre esta materia verán la luz en un futuro próximo y que formaron parte de la XIV Jornada sobre Derecho Marítimo en San Sebastián, celebrada el pasado 18 de mayo de 2006, organizada por la Escuela de Administración Marítima del Gobierno Vasco, con la colaboración del Departamento de Derecho de la Empresa de la Universidad del País Vasco (UPV-EHU). 
directa o indirectamente, derogue el presente Convenio, será considerada nula y sin efecto» ${ }^{25}$.

Por lo tanto, fuera de las posibilidades de pacto divergente que el propio CMR admita (p. ej., artículo 24), el régimen de responsabilidad del transportista es plenamente imperativo.

En todo caso, la nulidad a la que se refiere el artículo 41 CMR será de carácter parcial (en sus palabras: «no lleva aparejada la de las demás estipulaciones del contrato de transporte»).

En el sector marítimo, por su parte, el régimen de responsabilidad del transportista en régimen de conocimiento de embarque también tiene carácter imperativo, pero con carácter mínimo, es decir, el régimen legal de responsabilidad es inderogable para las partes, salvo que los pactos divergentes beneficien al derechohabiente. Si los pactos fuesen nulos, también aquí la nulidad será parcial.

Esta posición se desprende de los artículos 1(b), 3.8, 5 y 7 RHV $(2,4,10$, 13 y 17 LTM). Y también es la que recogen los artículos 2.3 y $23 \mathrm{RH}$ y el artículo 329 PALGNM.

\section{Periodo de responsabilidad}

Con esta expresión se describe el periodo de tiempo durante el cual el transportista responderá por el incumplimiento del contrato, si la pérdida, avería o retraso han sido causados por un hecho que sea reconducible a dicho periodo.

Generalmente, el periodo de responsabilidad del transportista comienza desde que se hace cargo de la mercancía en su origen hasta que la entrega (real o ficticiamente) en su destino. Y así lo establece inequívocamente el artículo 17.1 CMR para el transporte por carretera.

En el transporte marítimo, conceptualmente hablando, el periodo de responsabilidad también se define y delimita en unos mismos términos. La diferencia que se plantea en este sector es que no hay ningún precepto en las RHV (LTM) similar al artículo 17.1 CMR.

Lo que sí hay, pero no es lo mismo, es un precepto que delimita la extensión temporal del régimen imperativo de responsabilidad establecido por el Convenio (artículos 1.e RHV y 1 LTM), que como sabemos, acoge la regla llamada «tackle to tackle» (si bien con algunas complicaciones interpretativas añadidas por la redacción de la LTM). Es decir, el transportista marítimo es responsable desde que se hace cargo de la mercancía en origen hasta que la entrega en destino, pero su responsabilidad por las fases no marítimas del

${ }^{25}$ M. ZAAP, «Vertraglich begründete Überprüfungspflichten und Art. 41 CMR», TranspR (1991), 371. 
traslado se regirá no por las RHV (LTM) sino por las normas que resulten de aplicación a esas otras fases ${ }^{26}$.

Las RH (artículo 4) ${ }^{27}$ y la PALGNM (artículo 331) pretenden eliminar esta tradicional disfunción marítima reconduciendo el tratamiento normativo del periodo de responsabilidad del transportista marítimo a un sistema como el previsto en el CMR (si bien con algunas particularidades portuarias, que tendrán en cuenta la eventual intervención forzosa de autoridades o terceros en las fases previa y posterior al trayecto marítimo).

\section{Fundamento de la responsabilidad}

En esta materia, los sistemas terrestre (carretera) y marítimo se inspiran en un mismo modelo, el de presunción de responsabilidad (o de culpa): es decir, probado un incumplimiento contractual originado en el periodo de responsabilidad, se presume la responsabilidad del transportista, quien, para liberarse de dicha imputación de responsabilidad, deberá demostrar que el incumplimiento ha sido causado por uno de los hechos exoneradores previstos en la ley.

Éste es el sistema establecido en los artículos 17 y 18 CMR y, con cierta oscuridad y complejidad, en el artículo 4 RHV, apartados 1 , 2 y 4 (artículos 6,7 y 8 LTM). También lo acogen, por su parte, el anexo II y artículo 5 RH y el artículo 333 PALGNM.

Las divergencias entre ambos sistemas surgen con la formulación de las causas de exoneración.

En el CMR, acogiendo un sistema más elaborado, el transportista dispone de unas causas de exoneración generales y otras especiales.

Las causas generales de exoneración (artículo 17.2) son las siguientes: (a) la culpa del derechohabiente; (b) una instrucción de éste no derivada de una acción culposa del transportista; (c) el vicio propio de la mercancía; y (d) las circunstancias que el transportista no pudo evitar y cuyas consecuencias no pudo impedir ${ }^{28}$. La prueba de estas causas corresponde al transportista (artículo 18.1).

Las causas especiales de exoneración, por su parte, están recogidas en el artículo 17.4 y gozan de un régimen de prueba más beneficioso para el transportista que el del artículo 18.1 (artículo 18.2-5), por tratarse de riesgos específicos del transporte.

${ }^{26}$ D. Morán Bovio, Extremos del periodo de aplicación mínimo en la CB-PV, Madrid 1998. Del mismo autor, «Mercancías en la fase portuaria: problemas y soluciones», en Estudios Duque, II, Valladolid, pp. 1473 ss.

${ }^{27}$ D. Moran Bovio, «Los límites del periodo de la responsabilidad del porteador en las Reglas de Hamburgo», en Estudios Menéndez, III, Madrid 1995, pp. 3947 ss.

${ }^{28}$ C. M. CASHmore, «Circumstances which the carrier could not avoid», J. Bus. L. 344-345 (1983). 
Por su parte, en el sistema marítimo vigente, las causas de exoneración se recogen en un largo - y confuso - listado, deudor del casuismo anglosajón característico de este modo de trasporte (4.2 RHV, 8 LTM). Se trata, en cualquier caso, de causas que pueden reconducirse, de un modo u otro, a las categorías generales o especiales del transporte por carretera. Más concisas (pero abiertas) se manifiestan en este ámbito, sin embargo, las RH cuando aluden, como circunstancia exoneradora general, a la necesidad de que el porteador marítimo pruebe que sus empleados o agentes adoptaron todas las medidas que razonablemente podían exigirse para evitar el hecho y sus consecuencias $^{29}$.

Otras cuestiones particulares que cabría destacar en este ámbito:

1) Así como los defectos técnicos de los vehículos de transporte por carretera no se pueden aducir como causa de exoneración (artículo 17.3 $\mathrm{CMR}^{30}$, en el ámbito marítimo el transportista no será responsable de los daños derivados de la falta de navegabilidad del buque, a no ser que haya concurrido negligencia por su parte en este ámbito (artículos 4.1 RHV y 8 LTM) ${ }^{31}$.

2) No hay en el sector terrestre una posibilidad de exoneración como la que presentan las llamadas «faltas náuticas» en el transporte marítimo (artículos 4.2.a RHV y 8 LTM, párrafo tercero, letra $a$ ), particularidad marítima que, no obstante, desaparece en el sistema de las RH y de la PALGNM.

3) El incendio recibe un tratamiento específico en el transporte marítimo, del que no goza en el transporte por carretera ${ }^{32}$. En aquél, se presume su carácter fortuito y se pone sobre el demandante la carga de probar la negligencia del transportista en su causación o en la adopción de medidas para su extinción o atenuación (artículos 4.2.b RHV y 8.b LTM; también acogen esta peculiaridad marítima los artículos 5.3 RH y 333.2 PALGNM).

4) Los sistemas terrestre y marítimo coinciden en conceder un tratamiento particular al transporte de animales vivos, si bien las RHV (artículo 1c) (artículo 2 LTM) lo hacen para excluirlo del concepto de «mercancías»y, consiguientemente, para dejarlo fuera del ámbito de

${ }^{29}$ Un análisis comparativo en esta materia entre los principales textos internacionales marítimos puede encontrarse en R. HERBER, «The basis of liability of the carrier under the international conventions of carriage of goods by sea», Dir. Mar (1990), 493.

${ }^{30}$ K. H. Thume, «Die Haftung des CMR-Frachtführers für Fahrzeügmängel», RIW (1994), 357. En otro contexto, D. GLASS, «CMR and hired trailers.- A tilt too far?», [1981] 3 LMCLQ 384-388

31 Sobre esta cuestión, por todos, J. C. SÁEnz García de Albizu, La innavegabilidad del buque en el transporte marítimo, Madrid 1992.

32 J. C. SÁEnz García de Albizu, «La evolución de la excepción de incendio como causa de exoneración de la responsabilidad del porteador marítimo», $A D M(1990), 165$. 
aplicación de sus normas ${ }^{33}$, mientras que el CMR (artículo 17.4.f) lo considera un supuesto de riesgo específico del transporte y lo incluye entre los supuestos de prueba privilegiada (artículo 18.2), si bien con algunos matices (artículo 18.5). El futuro de la regulación marítima a este respecto, no obstante, aproximará el régimen marítimo al terrestre (artículos 5.5 RH y 334 PALGNM).

5) El tratamiento de la responsabilidad del transportista en los supuestos de desviación del vehículo (buque) de su ruta encuentra un acomodo clásico en el sector marítimo (artículos 4.2.1 y 4.4 RHV, 8.1 y 9 LTM, 5.6 RH y 288 PALGNM) ${ }^{34}$, pero no así en el ámbito del CMR, que no regula esta cuestión.

\section{Supuestos principales de responsabilidad}

La caracterización de los principales supuestos de responsabilidad del transportista es prácticamente universal en el sector del transporte (con independencia del modo). Habitualmente, el transportista responderá por la «pérdida», «avería» o «retraso» en la entrega de la mercancía.

De estos supuestos, el retraso es el que presenta algún interés desde la perspectiva de nuestro análisis ${ }^{35}$, pues así como en el ámbito del transporte por carretera, la correspondiente reglamentación le otorga un tratamiento específico, definiéndolo (artículo 19 CMR) y, en su caso, presumiendo la pérdida de la mercancía en caso de retrasos significativos (artículo 20 $\mathrm{CMR}^{36}$, la legislación marítima (RHV) ha prescindido de regularlo como supuesto de responsabilidad, sin perjuicio de la interpretación que a este respecto se ha propuesto del artículo 6 LTM, en cuya virtud cabría entender que el retraso también está previsto como supuesto de responsabilidad del transportista marítimo, si bien sujeto a posibles pactos exoneradores de responsabilidad, que, en este supuesto, no estarían prohibidos ${ }^{37}$. Este silencio (o indefinición) de la legislación marítima desaparece en las RH (artículo 5.2) y en el artículo 332 PALGNM, que dan un paso en el reconocimiento expreso del retraso como supuesto general de responsabilidad general del transportista marítimo.

${ }^{33}$ J.L. GoÑ EtcheVers, «El transporte de animales vivos», en AA.VV., Seminario sobre la responsabilidad del transportador de mercancías por agua (Buenos Aires), Milano 1983, pp. 77 ss.

${ }^{34}$ Por todos, J. C. SÁEnZ García De Albizu, El desvio de ruta en el transporte marítimo, Vitoria 1995.

${ }^{35}$ K. GRÖNFORS, «The concept of delay in transportation law», ETL (1974), 400.

${ }^{36}$ K. H. Thume, «Die Haftung des CMR-Frachtführers für Verspätungschaden», $R I W$ (1992), 966; A. C. HaRdinghaM, «The delay provisions of CMR», [1979] 2 LMCLQ $193-198$.

${ }^{37}$ En general, J. C. SÁEnz García de Albizu, «La responsabilidad del porteador por retraso en el transporte marítimo», Estudios Broseta, III, Valencia 1995, pp. 3355 ss. 


\section{Limitación de la deuda indemnizatoria}

Los transportes por carretera y marítimo comparten una misma posición de principio en materia de limitación de la deuda indemnizatoria del transportista responsable por pérdida y averías ${ }^{38}$. En ambos casos, está limitación se calcula sobre dos planos. Primero, sobre el valor de las mercancías perdidas o averiadas (daños directos). Y, en segundo lugar, sobre los importes monetarios máximos establecidos por la ley.

Con respecto al primer plano (valor de las mercancías), sin embargo, hay una divergencia significativa entre los dos modos de transporte considerados y es que, así como en el transporte por carretera el valor a tener en cuenta es de las mercancías en origen (artículo 23.1 CMR), en el transporte marítimo (artículos 4.5.b RHV y 11.b LTM) se trata del valor de las mercancías en destino, posición que comparte el artículo 335 PALGNM (las RH no dicen nada al respecto). El CMR y las RHV-LTM, por su parte, coinciden a la hora de proporcionar criterios orientadores para el cálculo de dicho valor (como, $\mathrm{p}$. ej., la cotización bursátil de las mercancías, su precio corriente en el mercado, su valor usual), aspecto este que, sin embargo, no ha sido objeto de atención por la PALGNM (tampoco por las RH).

Por lo que respecta a los límites cuantitativos legales, por otro lado, las diferencias entre el modo terrestre (carretera) y el modo marítimo se proyectan en dos ámbitos: uno, el método de cálculo; y otro, el número de unidades de cuenta que se establecen como límite.

En el sector de la carretera, los límites legales de indemnización se calculan sobre la base de los kilogramos de peso bruto de la mercancía que faltare (artículo 23.3 CMR) o que se hubiere averiado (artículo 25.2 CMR). En el sector marítimo, también se utiliza este criterio del peso bruto de la mercancía perdida o averiada (artículos 4.5.a RHV y 11.a LTM; igualmente, artículos 6.1.a RH y 335 PALGNM), pero, alternativamente, puede emplearse el criterio del bulto o unidad del cargamento (véanse los preceptos recién mencionados), pudiendo elegir el reclamante la cantidad más elevada que resulte de la aplicación de ambos criterios. Hay, por otro lado, una especialidad marítima adicional en este terreno y es la que introduce la conocida «container clause», para los supuestos de bultos o unidades de cargamento agrupa-

\footnotetext{
${ }^{38}$ En general, entre nosotros, en el sector del transporte por mar, véase el trabajo de J. L. RUEDA MARTíNEZ, «La limitación de la responsabilidad del porteador en el transporte marítimo de mercancías», ADM (1990), 19. Para el sistema del CMR en esta materia, H. GLöcKNER, «Limits to liability and liability insurance of carriers under articles 3 and 23 to 29 of the CMR», en J. Theunis (Gen. Ed.), International Carriage of Goods by Road (CMR), London 1987, pags. 97 ss. Del mismo autor, «Die Haftungbeschränkungen und die Versicherung nach den Art. 3, 23-29 CMR», TranspR (1988), 327. Igualmente, J. KNORRE, «Zur Haftung des Frachtführers nach Art. 23 u. 25 CMR», TranspR (1985), 241.
} 
dos en contenedores (artículos 4.5.b RHV, 11.c LTM, 6.2.a RH y 335.2 PALGNM) ${ }^{39}$.

También son distintos, como adelantamos, el número de unidades de cuenta (derechos especiales de giro o DEG) ${ }^{40}$ que se aplican en el transporte por carretera y en el transporte marítimo para calcular el límite máximo de indemnización. Mientras en el primero son 8,33 DEG, en el segundo son 666,67 DEG por bulto o unidad del cargamento o 2 DEG por kilogramo de peso bruto perdido o averiado (estas cantidades se modifican en las RH y en la PALGNM, que pasan a ser 835 DEG y 2,5 DEG respectivamente).

No es sustancialmente divergente, por su parte, el tratamiento que se le da en el transporte por carretera y el transporte marítimo a la cuestión de la posible modificación convencional de los límites indemnizatorios, pues en ambos casos se admiten pactos modificativos de las partes. Las diferencias, si se puede hablar de diferencias, estriban en los procedimientos habilitados en uno u otro caso para proceder a la referida modificación convencional de los límites de indemnización.

En el CMR hay dos procedimientos o sistemas perfectamente delimitados a este respecto: uno, la llamada «declaración de valor» (artículo 24 CMR); y otro, la llamada «declaración de interés especial en la entrega» (artículo $26 \mathrm{CMR}$ ). Fuera de ellos, no podrán ser reclamadas indemnizaciones de sumas superiores a las legalmente establecidas (artículos 23.6 y 41.1 CMR). Ambas declaraciones deberán fijarse en la carta de porte contra el

\footnotetext{
${ }^{39}$ Véase, entre otros, J. L. DE GuRSE, «The 'container clause' in article 4(5) of the 1968 Protocol to the Hague Rules», 2 J.Mar. L. \& Com. 131-146 (1970); T. BisSELL, «The operational realities of containerisation and their effect on the 'package' limitation and the 'ondeck' prohibition: Review and suggestions», 45 Tul.L.Rev 902-924 (1971); D. Zschoche, «Die Per-Package-Limitation beim transport in Containern», NJW (1978) 2421; T. J. ARMSTRONG, «Packaging trends and implications in the container revolution», $12 \mathrm{~J}$. Mar. L. \& Com. 427-465 (1981); L. B. AlEXANDER, «Containerization, the per package limitation and the concept of 'fair opportunity' (Comment)» 11 Mar.Law 123-140 (1986); G. M. BoI, «Applicazione del limite del debito del vettore ai containers», Dir.Mar. (1986), 574; ID., «Sull'applicabilità ai containers del limite del debito del vettore» (nota), Dir.Mar. (1986), 1067; ID., «Trasporto a mezzo contenitori e responsabilità del vettore marittimo: i primi orientamento della giurisprudenza italiana» (nota), Dir.Mar. (1989), 1074; ID., «Il trasporto marittimo a mezzo contenitori: la giurisprudenza italiana di fronte al dato normativo», Dir.Mar. (1994), 734; AA.VV., Il trasporto a mezzo contenitori: disciplina legale delle responsabilità, profili assicurativi e gestione delle liti, Seminario organizado por el Centro Ligure per la Produttività, bajo el patrocinio de la Camera di Commercio de Genova, 13-14 de octubre de 1994.

${ }^{40}$ Con alcance crítico, A. ToBolewsKi, «The special drawing right in liability conventions: an acceptable solution?», RDU/ULR (1978), II, 13; J. RAMBERG, «Monetary limits: CMR or national law», ponencia presentada en The European Inland Road Transport Law Conference (Eurotral'94), Erasmus Universiteit, Rotterdam, 24-25 de noviembre de 1994 y publicada en K. F. HAAK y E. C. SwART, Road carrier's liability in Europe, 2, Stichting Vervoeradres, The Hague 1995.
} 
pago de un sobreporte. La primera tiene como objeto declarar un valor de la mercancía superior a los 8,33 DEG por kilogramo de peso bruto, sustituyendo el montante declarado al legal. Y la segunda permitirá reclamar una indemnización igual al perjuicio suplementario que consiga probarse, además de la que, en su caso, corresponda en función de la aplicación de los límites legal o declarado del valor de la mercancía.

En el ámbito marítimo, por su parte, es admitida también la «declaración de valor» (artículos 4.5.a y h RHV y 11.a y f LTM; véase, igualmente, el artículo 335.1 PALGNM). Y si bien no se contempla un procedimiento específico como el de la «declaración de especial interés en la entrega», no puede decirse que la normativa marítima aplicable sea restrictiva en este particular, como demuestran las posibilidades que abren los artículos 4.5.g y 5 RHV, primer inciso (11.g y 13 LTM) (véanse, igualmente, los artículos 6.4 y 23.2 RH y, en general, 329 PALGNM).

Finalmente, por lo que respecta a los límites indemnizatorios en los casos de retraso en la entrega de las mercancías, el CMR (artículo 23.5) los cifra en una suma que no excederá el precio del transporte, siempre que se pruebe que el retraso causó un perjuicio. No hay, por razones que advertimos anteriormente, un tratamiento específico de esta cuestión en el régimen de las RHV (LTM), pero sí en las RH (artículo 6.1.b) y en la PALGNM (artículo 336.1), que establecen un límite de dos veces y medio el flete pagadero por las mercancías afectadas por el retraso, límite que podrá ser modificado convencionalmente (artículos 6.4 RH y 329 PALGNM). En la futura regulación marítima, por otro lado, se recoge, además, una regla específica aplicable a los supuestos de concurrencia de indemnizaciones por avería y retraso (artículos 6.1.c RH y 336.3 PALGNM), que es inexistente en el CMR y en las RHV (LTM).

\section{Pérdida del beneficio de la limitación de la deuda indemnizatoria}

La pérdida del beneficio de la limitación de la deuda indemnizatoria en determinadas circunstancias está recogida en todos los instrumentos del Derecho uniforme del transporte, incluidos los relativos al transporte por carretera y al transporte marítimo. Es el caso del artículo $29 \mathrm{CMR}^{41}$ y de los

${ }^{41}$ O. TuMA, «Art. 29 CMR. Bestandsaufnahme und Ausblick», ETL (1993), 649; ID., «Variations on the theme: "wilful misconduct" and "Große Fahrlässigkeit"», ponencia presentada en «The European Inland Road transport Law Conference (Eurotral'94)», Erasmus Universiteit, Rotterdam, 24-25 de noviembre de 1994 y publicada en K. F. HAAK y E. C. SwART, Road carrier's liability in Europe, 2, Stichting Vervoeradres, The Hague 1995. Igualmente, A. CHAO, «Dol, fraude ou infidelité et faute lourde du voiturier. Incidences sur la responsabilité, la réparation due et la recevabilité de l'action», BT (1990), 315; P. LuTZ, «Die Rechtsprechung der französischen Cour de Cassation zum Begriff des großen Verschulders des Frachtführers nach Artikel 29 CMR», TranspR (1989), 155. 
artículos 4.5.e y 4bis.4 RHV (11.e y 10.4 LTM), que acogen un régimen que es aplicable tanto a la responsabilidad del transportista como a la de sus auxiliares dependientes o independientes.

Las divergencias más significativas entre los sistemas propios de la carretera y del sector marítimo en esta materia residen en cómo se formulan normativamente las circunstancias en las que procede la pérdida del citado beneficio. Así, en el CMR, la pérdida se producirá cuando el daño haya sido causado por dolo o culpa equiparable al dolo por la ley del foro ${ }^{42}$. Mientras que en el sector marítimo se requiere que el daño sea el resultado de un acto o de una omisión del transportista, que se produce o con intención de provocarlo o temerariamente y con conocimiento de que probablemente del hecho se deducirá un daño.

\section{Aplicación del régimen de responsabilidad a las diversas acciones}

Para blindar el régimen de responsabilidad contractual previsto en sus normas, frente al posible ejercicio de acciones extracontractuales ${ }^{43}$, los instrumentos del Derecho uniforme del transporte por carretera y marítimo acogen una regla según la cual, en caso de reclamación aquiliana contra el transportista o sus auxiliares, éstos podrán ampararse en las disposiciones del correspondiente Convenio que establezcan exoneraciones o limitaciones de responsabilidad.

\footnotetext{
${ }^{42}$ P. IVALDI, «Wilful misconduct e colpa grave fra diritto internazionale e diritto interno», Riv.Dir.Int.Priv.Proc. (1989), 617. Entre nosotros, F. J. SÁNCHEZ-GAMBORINO, «La llamada culpa equiparable al dolo y sus consecuencias en el contrato de transporte», RDM (1995), 723.

${ }^{43}$ El problema de la concurrencia de acciones contractuales y extracontractuales en una misma situación ilícita ha suscitado una notable discusión doctrinal. En general, M. YZQUIERDO: «La zona fronteriza entre la responsabilidad contractual y la aquiliana. Razones para una moderada unificación», $R C D I$ (1991), 443. En el sector específico del transporte (sobre todo marítimo), F. SOLVENI, «Responsabilitá contrattuale ed extraconttratuale del trasporto marittimo di cose», Dir.Mar. (1960), 400; ID., «Sul concorso della responsabilitá conttratuale ed extraconttratuale nel trasporto marittimo di cose», Dir.Mar. (1969), 271; M. FALLON, «Le concours des actions en responsabilité: tâtonnements et certitudes de la Cour de Cassation de Belgique (Cass. 7. 12. 1973)», ETL (1974), 534; M. LÓPEZ DE GoNZALO, «Orientamenti della giurisprudenza in tema di concorso di responsabilitá contrattuale ed extraconttratuale nel trasporto marittimo di cose», Dir.Mar. (1984), 846; ID., «Il concorso di responsabilità conttratuale ed extraconttratuale nella Hague-Visby Rules e nelle altre convenzioni di diritto uniformi di trasporto», Dir.Mar. (1986), 611; C. MEDINA, «Ancora sul concorso o meno di responsabilità conttratuale e extraconttratuale del vettore aereo 0 sulla decadenza di responsabilità», Dir.Mar. (1989), 1138.
} 
En este sentido se pronuncian los artículos $28 \mathrm{CMR}^{44}$ y 4 bis RHV (10 bis LTM) (también los artículos 7 RH y 337 PALGNM) ${ }^{45}$.

El único matiz diferenciador, si bien relevante, sobre este particular es que en el sector del transporte marítimo (RHV-LTM) la protección que dispensa esta regla uniforme no se extiende a los auxiliares independientes del transportista marítimo («contratistas por cuenta propia»), sino sólo a los auxiliares dependientes. La protección de aquéllos, en su caso, podrá articularse a través de la inserción en el documento de transporte de la llamada «cláusula himalaya», de frecuente pero debatida utilización en el tráfico ${ }^{46}$. Esta posición está llamada a cambiar en las RH y la PALGNM, que propugnan un régimen semejante al CMR.

\section{Protestas}

La facultad que tiene el destinatario de la mercancía para realizar protestas sobre su estado o situación en el momento de su entrega es muy relevante a los efectos de reforzar su posición de ataque de cara a una eventual reclamación. No es de extrañar, por tanto, que todos los instrumentos de Derecho uniforme del transporte aborden esta cuestión con la debida atención y que

${ }^{44}$ O. Tuma, «Zur Frage der Möglichkeit der Geltendmachung deliktischer Ansprüche wegen Güterschäden gegen im internationalen Straßengüterverkehr tätige Frachtführer unter besonderer Berücksichtigung der Stellung der Person des Anspruchstellers als Vetragspartner bzw. als außervertraglicher Dritter zum in Anspruch Genommenen sowie zur Frage, ob deliktische Ansprüche nicht am Frachtvertrag Beteilgter durch vertragliche Bestimmungen eingeschränkt werden konnen-CMR Art. 28, 32», ETL (1983), 3.

${ }^{45}$ En general, en el sector marítimo, J. M. RuIz SoroA, «Aplicación del régimen jurídico propio de las acciones de responsabilidad por averías o pérdidas en el cargamento o daños al pasajero», III Jornadas de Derecho marítimo de San Sebastián, San SebastiánDonostia 1996, pp. 89 ss. Igualmente, G. RIGHETTI, «Responsabilitá conttratuale e responsabilitá extraconttratuale del vettore marítimo e del noleggiante», Dir.Mar. (1961), 569; K. GRÖNFORS, «Non-contractual claims under the Hamburg Rules», en S. MANKABADY (Ed.), The Hamburg Rules on the carriage of goods by sea, Leyden-Boston 1978, pp. 187 ss.; F. M. B. REYNOLDS, «The significance of tort claims in respect of carriage by sea», (1986) 1 LMCLQ 97-111.

${ }^{46}$ Sobre esta cláusula y otros aspectos próximos, J. B. DOAK, «Liabilities of stevedores, terminal operators and other handlers of cargo», 45 Tul.L.Rev. $752-769$ (1971); S. CigoJ, «Legal relations of stevedores in comparative law», (1975) 3 LMCLQ 296-302; W. TETLEY, «The Himalaya clause. Heresy or genius», 9 J.Mar.L.Com. 111-130 (1977-1978); D. G. Powles, «The Himalaya Clause», (1979) 3 LMCLQ 331-346; J. ZAWITOSKI, «Limitation of liability for stevedores and terminal operators under the carrier's bill of lading and Cogsa», 16 J. Mar. L. \& Com. 337-363 (1985); C. D. HoOPER, «Legal relationships: terminal owners, operators and users», 64 Tul.L.Rev. 595-609 (1989); AA.VV., «Symposium on terminal operations and multimodalism», Admiralty Law Institute, Tulane Law School, 64 Tul. L. Rev. 281-629 (1989); S. Hilton, «The Himalaya Clause in South Africa. The Sanko Vega (Case and Comment)», (1992) 3 LMCLQ 317-322; N. GASKELL, «Shipowner liability for cargo damage caused by stevedores. The Coral (Case and Comment)», (1993) 2 LMCLQ 170-177. 
lo hagan, en cierto modo, de una manera semejante en todos ellos, si bien no se caracterizan, en su mayoría, por su simplicidad y sistematicidad.

Así, por un lado, tanto el CMR (artículo 30) ${ }^{47}$ como las RHV (artículo 3.6; también, artículo 22 LTM) ofrecen al destinatario dos procedimientos de protesta: uno, las reservas (CMR) o avisos (RHV-LTM); y, otro, la inspección conjunta o verificación contradictoria de la mercancía. En un mismo sentido se pronuncian los artículos 19 RH y 340 PALGNM.

Tratándose del segundo de los procedimientos, el CMR establece que «la prueba contraria al resultado de esta verificación no será admisible más que si se trata de pérdidas o averías ocultas y siempre que el destinatario haya dirigido reservas escritas al transportista en el plazo de siete días, descontados domingos y festivos, desde esta verificación» (artículo 30.2). La normativa marítima se limita a establecer que «las reservas por escrito son inútiles si el estado de la mercancía ha sido comprobado contradictoriamente en el momento de la recepción» (artículos 3.6 RHV, párrafo segundo y 22 LTM, párrafo tercero).

En el caso de reservas o avisos, por su parte, se exige, en primer lugar, que se hagan por escrito (artículo 3.6 RHV, primer párrafo y artículo 22 LTM, primer párrafo), si bien en el CMR (artículo 30.1), este requisito sólo se establece expresamente para los casos de pérdidas o averías ocultas. Y, en segundo lugar, deben ser hechas dentro del plazo establecido, que en caso de pérdidas o averías aparentes será el mismo momento de entrega de las mercancías (posición compartida por el CMR y las RHV-LTM, no así por las RH o la PALGNM, que lo extienden hasta el día laborable siguiente a la entrega); y en el caso de pérdidas o averías no aparentes (u ocultas) será de siete días desde la fecha de entrega, en el CMR, o de los tres días laborables siguientes a la entrega, en el caso de las RHV-LTM (éste es también el plazo acogido por la PALGNM, pero no por las RH, que lo fijan en 15 días).

Pero, quizás, lo más relevante del régimen de las protestas (en particular, de los avisos o reservas) sea la determinación de sus consecuencias o, para ser más precisos, de las consecuencias derivadas de la omisión de reservas o de su realización fuera de plazo. En este aspecto, el transporte por carretera y el transporte marítimo siguen una misma regla: a falta de reservas válidamente realizadas, se presumirá (iuris tantum) la recepción de las mercancías por el transportista en el modo descrito en la carta de porte. Esta consecuencia, por su parte, alcanza también a los supuestos en que no se hubiere procedido a la correspondiente inspección conjunta o verificación contradictoria.

${ }^{47}$ R. LOEWE, «The CMR provisions concerning claims and actions», en J. TheunIS (Gen. ed.), International Carriage of Goods by Road (CMR), London 1987, pags. 145 ss. Igualmente, del mismo autor, «Die Bestimmungen der CMR über Reklamationen und Klagen», TranspR (1988), 309. 
En el caso de que el supuesto de responsabilidad considerado sea el retraso, una vez más tan sólo el CMR alude al régimen de protestas. Y lo hace en su artículo 30.3 cuando señala que «el retraso en la entrega no dará lugar a indemnización más que en el caso de que se haya dirigido reserva por escrito al transportista dentro del plazo de veintiún días desde la puesta de la mercancía a disposición del destinatario». Una previsión semejante no aparece en el sistema de las RHV-LTM, por razones conocidas, pero sí en las RH (artículo 19.5), aunque no en la PALGNM. Las RH exigen dar aviso por escrito dentro de un plazo de 60 días desde que las mercancías debieron ser entregadas y, en caso contrario, establecen también la preclusión del derecho a la indemnización de daños y perjuicios.

Finalmente, coinciden CMR (artículo 30.5) y las RHV-LTM (artículos 3.6, párrafo cuarto, y 22, párrafo quinto, respectivamente; igualmente, véase el artículo 19.4 RH) en establecer una regla en cuya virtud se exige a las partes que se den recíprocamente toda clase de facilidades para la inspección de la mercancía y para la realización de las constataciones y verificaciones necesarias. Este régimen no aparece en la PALGNM.

\section{Prescripción}

En esta materia, el CMR (artículo 32.1, primer párrafo) establece unos plazos de prescripción de las acciones derivadas del contrato de transporte que son, en concreto, de un año (plazo general) o de tres años, este último previsto especialmente para los supuestos de acciones basadas en el artículo $29 \mathrm{CMR}$ (existencia de dolo o culpa equiparable al dolo). La regulación del CMR en esta materia se completa con la determinación del comienzo del plazo de prescripción (artículo 32.1, segundo párrafo), con unas polémicas reglas relativas a la interrupción y suspensión de la prescripción (artículo 32.2 y 3 ) ${ }^{48}$ y, finalmente, con la indicación de los efectos derivados de la prescripción (artículo 32.4). También, el CMR regula, si bien en otra sede, la prescripción de las acciones de repetición en los casos de transportes sucesivos aunque con una remisión al régimen general del artículo 32 (artículo 39.4) ${ }^{49}$.

${ }^{48}$ R. DE WIT, «La formulation de réserves et la suspension de la prescription sous l'empire de la C.M.R. Note sous Comm. Bruxelles 2 avril 1990», ETL (1991), 547; D. DE BEULE, «L'article 32.2 CMR», ETL (1988), 654; C. M. CASHMORE, «CMR limitation period; suspension of period by virtue of written claim», J. Bus. L. 172-173 (1985); R. DE ÁNGEL YAGÜEZ, «Interrupción y suspensión de la prescripción. Convenio de Ginebra sobre transportes por carretera», La Ley (1987-4), 213; J. KNORRE, «Die Person des Reklamierenden im Sinne des Art. 32 Abs. 2 CMR», TranspR (1989), 308.

${ }^{49}$ En general, sobre el régimen de la prescripción en el CMR, véase J. WETTER, «The time bar regulations in the CMR convention», [1979] 4 LMCLQ 504-509; A. C. HARDINGHAM, «Aspects of the limitation of actions under CMR», [1979] 3 LMCLQ 362-367; A. EMPARANZA SOBEJANO, «La prescripción de las acciones en el Convenio relativo al contrato de transporte internacional de mercancías por carretera (CMR)», $R G D(1992), 11713$; A. L. 
En el ámbito de las RHV (LTM), por su parte, esta cuestión está regulada en su artículo 3.6, párrafo cuarto (artículo 22 LTM, párrafo cuarto), donde se afirma que «el porteador y el buque quedarán descargados de cualquier responsabilidad relacionada con las mercancías a menos que se entable la acción correspondiente dentro de un año, a contar desde la entrega de las mismas, o desde la fecha en que hubieren debido entregarse». Se coincide, por tanto, con el plazo general del CMR (un año), pero ahí se detienen los parecidos. Así, la determinación del dies a quo en el régimen marítimo es menos precisa que en el CMR. Y, por otro lado, y mucho más relevante, el plazo de las RHV-LTM, según postura unánime, no es de prescripción, sino de caducidad, aunque las RHV-LTM permiten la prórroga de dicho plazo mediante acuerdo concertado entre las partes con posterioridad al hecho que dio lugar a la correspondiente acción.

La regulación de esta materia en las RH está recogida en su artículo 20. Y también en el artículo 341 de la PALGNM (o en su artículo 330.4, para la acción de repetición en los supuestos de concurrencia de porteadores contractual y efectivo). Tanto en uno como en otro instrumento, el plazo de prescripción, que será tal (y no de caducidad), es de dos años.

\section{Conclusiones}

La política comunitaria en el sector del transporte ha hecho una apuesta innegable por el TMCD. Por un lado, para revitalizar un sector en claro declive. Y, por otro, para impulsar su inserción en el marco de operaciones de transporte multimodal más eficientes, rápidas, seguras y respetuosas con el medio ambiente. Nos parece una política muy sensata.

Desde un punto de vista jurídico-contractual, las operaciones de transporte con TMCD plantean, sin duda, ciertas incertidumbres, en parte porque no hay un modelo estructural único que configure jurídicamente a dichas operaciones; y, también, por la inevitable superposición contractual y de regímenes, más o menos divergentes entre sí, que caracteriza a este tipo de operaciones. Pero esta apreciación, llamémosla negativa, no debe impedirnos apreciar los aspectos positivos del actual estatus jurídico aplicable a las operaciones de transporte con TMCD. Es cierto que no contamos con un régimen uniforme aplicable a los distintos modos de transporte ${ }^{50}$, situación

Monge GIL, «Transporte internacional de mercancías. Prescripción (Comentario a la sentencia del Tribunal Supremo de 24 de febrero de 1995)», CCJC (1995), 767, ref. 1036; A. PÉREZ MORIONES, «La regulación de la prescripción de las acciones en el Convenio de Ginebra de 19 de mayo de 1956, relativo al contrato de transporte internacional de mercancías por carretera», RdP (1999), 203.

${ }^{50} \mathrm{~S}$. ZAMORA, «Carrier liability for damages or loss to cargo in international transport», 23 Am. J. Comp. L. 391 (1975). Y aun así, siempre tendríamos el problema de la divergente aplicación nacional del correspondiente régimen uniforme. Como botón de muestra, CH. DE BATTISTA, «Carriage conventions and their interpretation in English Courts», J. Bus. L. 130-142 (1997); D. J. HILL, «The interpretation of CMR in the English courts», [1977] 2 LMCLQ 212-217. 
que algunos calificarán de utópica. Y que ni siquiera se ha conseguido alcanzar un consenso sobre una regulación uniforme del transporte multimodal. Pero debemos recordar que, al menos en el contexto comunitario o europeo, contamos con un precepto, el artículo 2 CMR, que, no obstante sus dificultades interpretativas y de aplicación, contempla, precisamente, un modelo de estructuración del transporte que responde fielmente a las exigencias que plantean las operaciones de transporte con TMCD o, por ser más precisos, de un buen número de dichas operaciones. Cabría recomendar, sin duda, una reforma de dicho precepto, para clarificar su aplicación y alcance, en los términos sugeridos por la doctrina que lo ha criticado. Pero el precepto está ahí y puede dar un juego adecuado en el contexto de la utilización del TMCD en operaciones de transporte multimodales. Y, por otro lado, también están ahí el CMR y las RHV (LTM) como instrumentos reguladores de las diferentes fases, etapas o relaciones implicadas en las operaciones de transporte con TMCD, para proporcionar la suficiente confianza a los operadores que intervienen en este sector. Una confianza que proviene de la solera de dos cuerpos normativos que, sin perjuicio de sus defectos (mayores o menores, según el caso) han sido objeto de una aplicación solvente y regular por parte de los operadores jurídicos a lo largo del tiempo. Probablemente, la labor pendiente sea la de proporcionar a los operadores del transporte por carretera la suficiente información acerca del alcance de la regulación marítima vigente (RHV), labor esta que, dicho sea de paso, vendría facilitada por una eventual entrada en vigor entre nosotros y los países de nuestro entorno de las RH, que responden a un modelo de regulación del contrato de transporte más próximo al CMR que a las RHV. Pero esto, pensarán algunos, también puede ser una utopía ${ }^{51}$.

\footnotetext{
${ }^{51}$ Para una valoración de las RH, desde distintas aproximaciones, pueden consultarse los trabajos de K. GRÖNFORS, «The Hamburg Rules. A failure or success?», J.Bus.L (1978), 334; S. KATZ, «New momentum towards entry into force of the Hamburg Rules», ETL (1989), 297; C. K. NubuPKo, «La Convention des Nations Unies sur le transport international de merchandises par mer dix ans après», DMF (1989), 539; L. DelwAIDE, «The Hamburg Rules: a choice for the EEC?», Dir.Mar. (1994), 74; B. MAKINS, «The Hamburg Rules: A casualty?», Dir. Mar. (1943), 637. Véase, igualmente, desde otra perspectiva, D. MoRÁN Bovio, «Primeras sentencias en aplicación de las Reglas de Hamburgo», RGD 627 (1996), 13303.
} 